is so characteristic that it sufficed, without any other aids to diagnosis, for the exact localization of the tumour in a series of 24 patients, all of which cases were verified surgically.

M. Hamblin Smith.

A Case of Narcoleptic Cataplexy, Probably of Encephalitic Origin [Cataplexia narcoléptica, provávelmente encefalitica]. (Rev. da Assoc. Paulista de Med., vol. iii, p. 183, Oct., 1933.) Vampré, E., Sobrinho, P., and Ribeiro, J.

Observations upon narcoleptic cataplexy are rare. The authors give a detailed description of a case. They believe that the phenomena presented by the disease depend upon a larval type of epidemic encephalitis. The syndrome consists of a repetition of crises manifested by a general or localized loss of positional tone and of muscular power. It is never easy to eliminate entirely the possibility of simulation.

M. Hamblin Smith.

\title{
5. Treatment.
}

Mechanism of the Action of Calcium and Potassium Salts Injected into the Cerebral Ventricles. (Compt. Rend. Soc. Biol., vol. cxiv, p. 674, 1933.) Stern, L., Rossine, J. A., and Chroles, G. J.

The direct action of calcium on the vegetative nervous centres of the brain consists of an excitation of the parasympathetic centres (vaso-dilator and cardiac inhibitor), but a possible inhibitor effect on the sympathetic centres is not excluded. Potassium excites the vaso-constrictor and cardiac centres and probably indirectly weakens the tonus of the parasympathetic centres

L. E. Gilson (Chem. Abstr.).

Alkalosis and Excitability of the Cortical Sensory-motor Centres. (Arch. fisiol., vol. xxxii, p. 361, 1933.) Martino, G., and de'Finis, $L$.

Oral doses of 2-10 grm. of $\mathrm{CaCl}_{\text {, or }} \mathrm{HN}_{4} \mathrm{Cl}$ have no influence on the excitability of the cortical centres of the dog. Pulmonary hyperventilation after doses of these salts does not cause changes, whereas it increases the excitability in non-treated dogs. The latter effect is probably caused by alkalosis.

A. E. Meyer (Chem. Abstr.).

The Barbituric Acids: Their Toxicology. (Thesis, Lille, 1932.) Desodt, C.

The properties, uses, toxicology and colour reactions of five important barbituric acid hypnotics are reviewed. The original work consists in the application of a new method for isolation of barbituric acids from the urine. To $250-300$ c.c. of urine

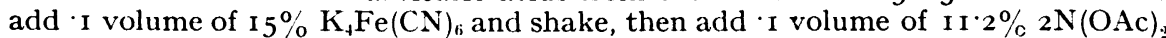
and mix with a stirrer. Filter, and if the filtrate is not acid, add a few drops of $\mathrm{AcOH}$. Transfer to a separating funnel, add 75 c.c. of ether, mix carefully at first, then more vigorously, draw off the aqueous layer and repeat the extraction four times. Dry the combined extracts for 20 minutes with anhydrous sodium sulphate and filter through cotton. Evaporate the ether on a water-bath, extract the residue with 1o-20 c.c. or boiling ethyl alcohol, filter into a weighed dish and evaporate. A white residue is assumed to be pure barbituric acid, and the percentage is calculated from the volumes of urine and of the various filtrates. If the residue is coloured, it is extracted with $20-30$ c.c. of boiling water and treated with animal charcoal for I 5 minutes or until the colour is removed, then evaporated and weighed. The recovery of barbituric acid (barbital, rutonal, gardenal, dial and soneryl) is $89-96 \%$ of the amount present. Essentially the same procedure is said to be applicable to blood, gastric contents and cerebro-spinal fluid. Daily excretion by hospital patients during daily doses for the period indicated averaged : 